\title{
50 Jahre nach „Kiel“ - Zeit zum Mitgestalten
}

\section{Heiner Schote ${ }^{1}$}

Online publiziert: 2. Dezember 2019

(c) Deutscher Verband für Angewandte Geographie (DVAG) 2019

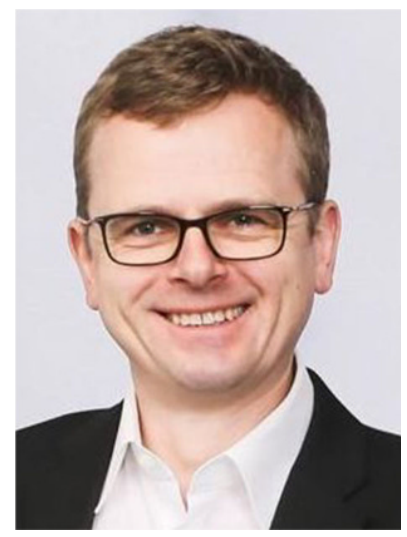

(c) Ulrich Perrey

Erneut trafen sich in diesem Herbst - 50 Jahre nach dem ,legendären" Kieler Geographentag von 1969 - Geographinnen und Geographen in der schleswig-holsteinischen Landeshauptstadt. Vieles hat sich seither verändert: Deutschland und Europa sind wiedervereinigt - auch wenn es im Moment den Anschein hat, als seien nicht alle darüber so glücklich wie vor 30 Jahren, als die Berliner Mauer ihren Schrecken verlor. Die Vereinigten Staaten sind dabei, ihre Führungsrolle zu verteidigen gegenüber dem immer einflussreicheren China, das sich - zu Recht - wieder als „Reich der Mitte“" versteht.

Vor dem Hintergrund dieser umfassenden geopolitischen Neujustierung muss sich auch Deutschland neu positionieren. Zugleich gilt es, das Klima zu schützen, mit mehr Viel- falt umzugehen: in den Metropolen ebenso wie in ländlichen Regionen. Und wir müssen den Menschen, egal, ob begünstigt oder benachteiligt, neue Perspektiven für ihr Leben eröffnen.

Die Geographinnen und Geographen können hierzu ihren Beitrag leisten; anders als vor einem halben Jahrhundert vertreten sie nicht nur an den Schulen und Hochschulen ein wichtiges Fach, sondern längst spielen sie auch in der beruflichen Praxis, in der Privatwirtschaft ebenso wie im öffentlichen Sektor, eine wichtige Rolle: als Wirtschaftsförderer, als Umweltexperten, als Stadtentwickler, als Consultants oder als Organisationsexperten in großen Unternehmen. Einen Eindruck von der Vielfalt der Themen, mit denen sich Geographen and und Geographen befassen, gewinnen Sie auch beim Lesen dieses Heftes.

Für viele ist der Geographentag von Kiel 1969 mit dem Ende der Landeskunde verbunden. Mindestens ebenso wichtig ist, dass der Kieler Geographentag auch einen Aufschwung für die Angewandte Geographie mit sich gebracht hat. Ein Grund mehr, die sich verändernde Welt nicht nur zu beobachten und zu bewerten, sondern auch mitzugestalten.

Viel Spaß beim Lesen dieses Hefts und beim Mitgestalten dieser Erde!

Heiner Schote

Mitglied des STANDORT-Fachbeirats

Heiner Schote

heiner.schote@hk24.de

1 Hamburg, Deutschland 